Gdańsk University of Technology, Faculty of Mechanical Engineering, Narutowicza 11/12, 80-233 Gdańsk, Poland

mlandowski@gmail.com

\title{
IMPACT BEHAVIOUR OF GLASS FRIBRE /EPOXY COMPOSITES WITH NANO-ENHANCED RESIN AFTER WATER EXPOSURE
}

\begin{abstract}
Impact behaviour of glass fibre /epoxy composites with nano- $\mathrm{SiO}_{2}$ modified resin was studied in terms of low velocity impact after water exposure. Nanocomposites with $1 \%, 2 \%, 3 \% 5 \%$ 7\% nano-SiO ${ }_{2}\left(\mathrm{Nanopox}_{\text {- Evonic) }}\right.$ were investigated. Peak impact load and impact damage area as a function of nanoparticle contents were compared for dry specimens and for samples exposed to water $(0.7 \%$ wt. $1.7 \%$ water absorbed) at $1 \mathrm{~J}, 2 \mathrm{~J} 3 \mathrm{~J}$ impact energies. For unmodified composite peak force was higher than for 3\% modified specimens and higher for dry specimens than those exposed to water. Impact damage areas were plotted as a function of water contents for modified and unmodified samples. Failure modes were illustrated using SEM micrographs. Numeropus matrix cracks were the dominating failure mode in dry speciemens both unmodified and the modified. Fibre fracture was observed at $3 \mathrm{~J}$ impact energy in all dry unmodified samples, however water exposure prevented early fibre fracture in nanocomposites. The proposed energy absorption mechanism is nanoparticles debonding.
\end{abstract}

Keywords: Polymer composites, nano-composites, low velocity impact

\section{INTRODUCTION}

In the recent years there has been a rapid growth in the use of fbre reinforced composite materials in engineering applications. However, the poor tolerance to accidental low velocity impacts of composite laminates is yet a limitation to their use in many industrial applications [1]. According to the some reports $[1,2]$ adding low concentrations of nanoparticles into polymers is a good solution to improve their mechanical and impact performance without compromising on density, toughness or manufacturing process. Hosur et al [3] showed that the addition of nanoclay in carbon/epoxy composites decreases the impact damage as a consequence of higher stiffness and resistance to damage progression of the nanophasereinforced laminates. The potential of nanoparticles as reinforcement of epoxy resins is clear due to the very large surface of interaction with polymer matrix. However, nanoparticles form agglomerates which are difficult to disperse even after intense mixing. Therefore, development of nano-products in which $\mathrm{SiO}_{2}$ nanoparticles are evenly distributed in basic resin and ready to be mixed with the matrix resin was an important step forward in nanoparticle materials processing. $\mathrm{SiO}_{2}$ nanoparticles are chemically synthesized from aqueous sodium silicate solution. In this process the binding agent is not damaged in contrast to the processes in which powdered fillers are dispersed with dissolvers or some equipment using high shear energy. The spherical silica is distributed agglomerate free in the matrix resin. This results in a very low viscosity of the dispersion with $\mathrm{SiO}_{2}$ contents of up to $40 \mathrm{wt} . \%$ 
[4]. Zheng et al. used $15 \mathrm{wt} . \% \mathrm{SiO}_{2}$ nanoparticles as Nanopox ( Evonic) to modify epoxy resin in carbon epoxy laminate which resulted in 20-30\% improvement of fracture toughness $\mathrm{G}_{\mathrm{Ic}}$, and obtained $40 \%$ increase in Young's modulus in glass fibre reinforced laminate using $15 \% \mathrm{SiO}_{2}$ nanoparticles as epoxy matrix modifier [5]. The positive $\mathrm{SiO}_{2}$ nanoparticles effect on the flexural strength of similar material was demonstrated in [4] using VARTM laminate processing technique.

Sice the authors were previously involved in the study of water immersion effect on impact behaviour of fibre reinforced/ epoxy composites [6] and laminates with $\mathrm{SiO}_{2}$ nanoparticles modified surface layers [7] the aim of the present study was to determine the effect of $\mathrm{SiO}_{2}$ nanoparticles on combined water immersion and impact behaviour in reinforced-glass fibre epoxy laminates processed by hand lay up technique still used in small ship construction companies.

\section{EXPERIMENTAL PROCEDURE}

Glass fibre-reinforced polymer (GFRP) laminates were investigated in this study with Hexion L285 DGEBA epoxy resin as matrix (curing agent 285). 0\%, 1\%, 2\%, 3\%, 5\%, 7\% wt. $\mathrm{SiO}_{2}$ nanoparticles (Nanopox A410 supplied by Evonic) were added to the matrix. Nanopox A 410 is a suspension of $\mathrm{SiO}_{2} 20 \mathrm{~nm}$ i diameter $(40 \% \mathrm{wt})$ in Basic epoxy resin DGEBA to be mixed with epoxy resins [4]. The reinforcement was orthogonal glass fibre fabric $620 \mathrm{~g} / \mathrm{m}^{2}$ (5 plies $80 \mathrm{~g} / \mathrm{m}^{2}$ and two plies $\left.110 \mathrm{~g} / \mathrm{m}^{2}\right) .6$ sheets were formed using hand lay-up method, and cured for 24 hours in ambient temperature then postcured in $70^{\circ} \mathrm{C}$ for 24 hours. Specimens $100 \times 100 \times 1 \mathrm{~mm}$ were conditioned in water at $50^{\circ} \mathrm{C}$ up to ca. $2.2 \%$ wt., water contents. Next low velocity impact tests were performed using conditioned and dry samples. Impact tester was drop weight Tower Instron CEAST 9310 with $20 \mathrm{~mm}$ spherical tip. Dynamic impact behaviour was recorded using DAS 64 K-S.C. recorder. Impact energy was: 1J, 2J, 3J. Next the macrophotographs of the specimens surfaces were taken and impact damage area was assessed by image analysis software Multiscan. SEM (Philips XL 30 ESEM) micrographs were taken of impacted specimens' sections so as to illustrate impact damage.

\section{RESULTS AND DISCUSSION}

Fig. 1 compares dynamic force -time impact characteristics at $3 \mathrm{~J}$ impact energy for unmodified specimens (Fig. 1a) and specimens with 3\%wt. nanoparticles (Fig. 1b) both in "dry" condition or with $0.7 \%$ and $1.7 \%$ water absorbed. Smooth curve profile for "dry" and $0.7 \%$ water (Fig. 1a) indicates that only minor impact damage resulted in these specimens whereas at higher water contents $(1,7 \%)$ more severe fibre damage resulted. Addition of $3 \% \mathrm{SiO}_{2}$ (Fig. 1b) changes the failure mode of "wet (1.7\% water) specimens compared to the dry $\left(3 \% \mathrm{SiO}_{2}\right)$ and to the unmodified $\left(0 \% \mathrm{SiO}_{2}\right)$. At $3 \mathrm{~J}$ impact energy, dry (and $0.7 \%$ water) $3 \% \mathrm{SiO}_{2}$ modified specimens are subjected to fibre breakage whereas in wet condition $(1.7 \%$ water) smooth load-time curve is observed which is indicative of minor damage (matrix cracks) and a positive nano-particle effect. Fig 2 a illustrates slightly decreased peak impact load for $\mathrm{SiO}_{2}$ modified specimens. This property remains practically unchanged after water exposure (up to 2\% water absorbed). However failure modes are different. Energy absorbed (Fig. 2b) decreased with increased water amount and absence of nanoparticle effect was observed. 
(a)

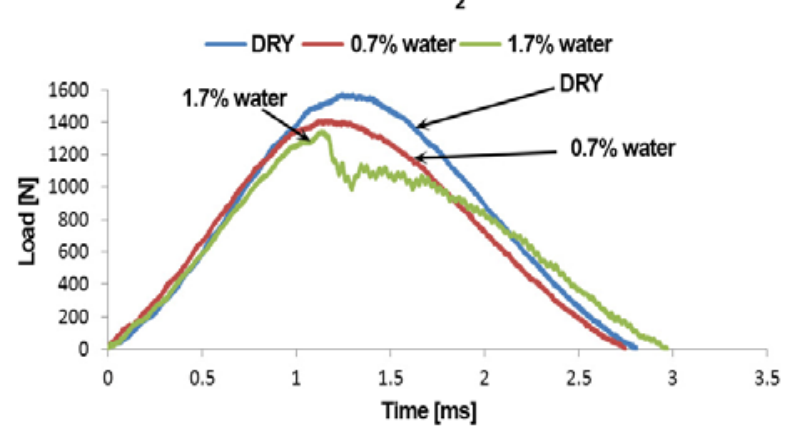

(b)

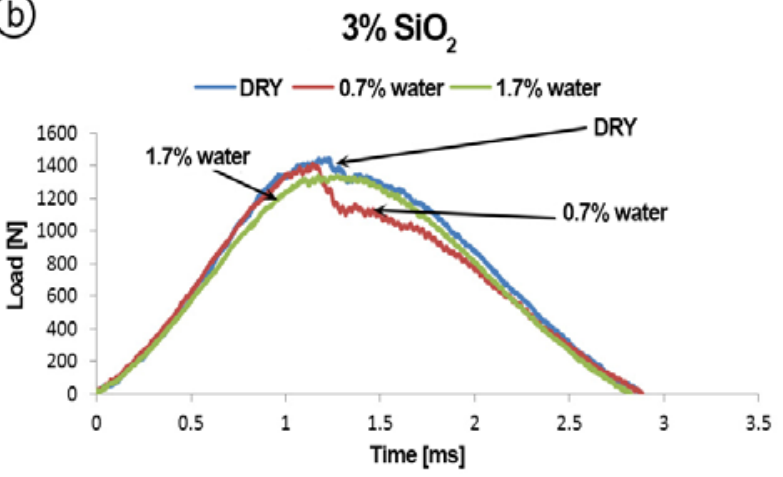

Fig. 1. Impact load-time characteristics for (a) unmodified, (b) $3 \%$ nanoparticle modified specimens in dry and wet conditions (with variable water contents). Impact energy $3 \mathrm{~J}$

(a)

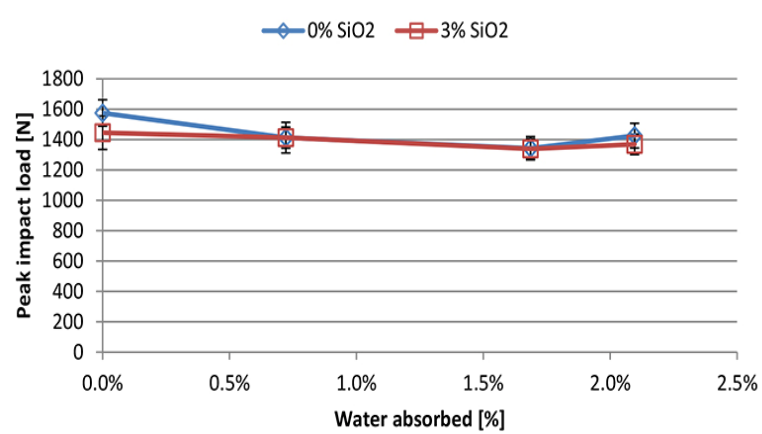

(b)

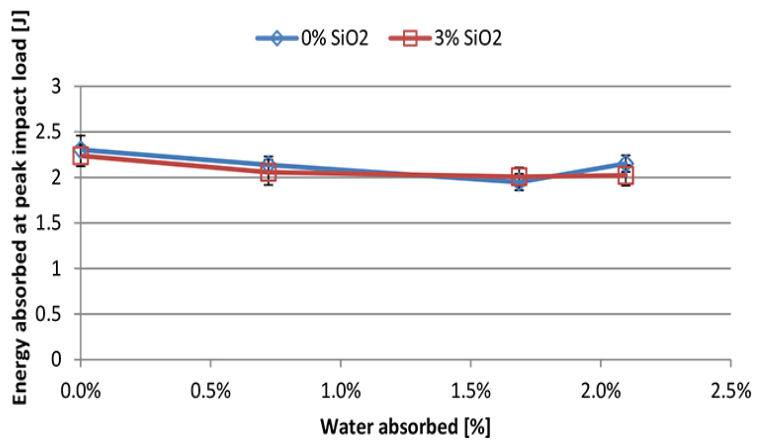

Fig. 2. a) Peak impact load as a function of amount of water absorbed by the specimens with $0 \%$ and $3 \%$ nanoparticles, b) energy absorbed at peak impact load as a function of amount of water absorbed by the specimens with $0 \%$ and $3 \%$ nanoparticles. Impact energy $3 \mathrm{~J}$

Fig. 3 illustrates impact damage in laminates modified with 1-7\% nanoparticles in dry (upper row) and wet ( $0.5 \%$ water absorbed). The shape of impacted zone differs slightly due to different failure modes, however impact damage area (Fig. 4) is 10-15\% lower for unmodified specimens. The improvement in the behaviour of $3 \% \mathrm{SiO}_{2}$ modified specimens is observed in terms of impact damage area for "wet" (1-2\% water absorbed) specimens. 
3J $0 \% \mathrm{SiO}_{2}$

$1 \%$
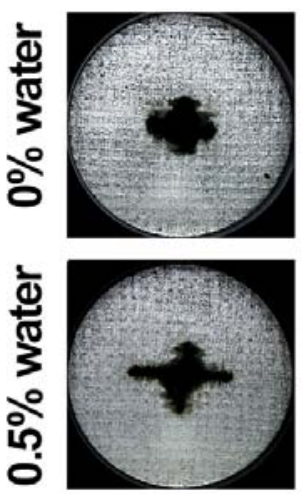

$2 \%$
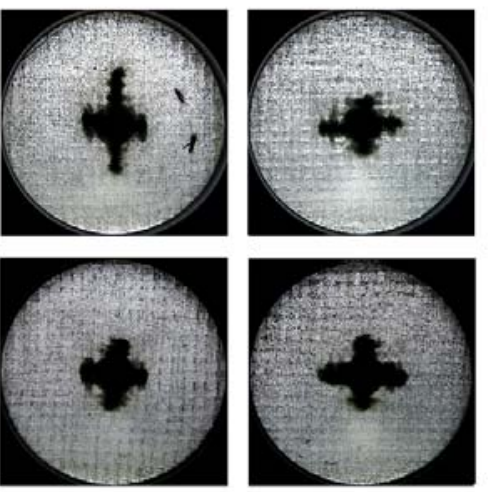

$3 \%$

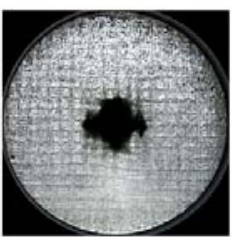

$5 \%$
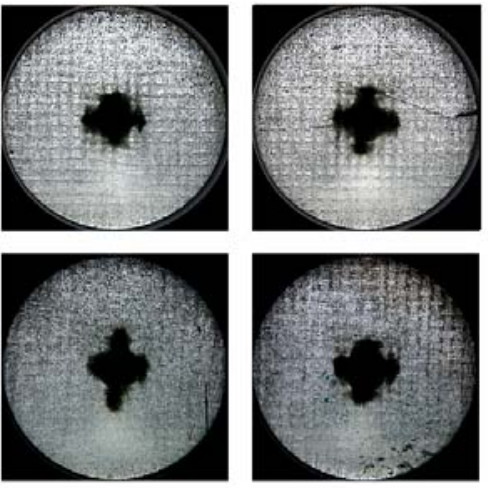

$7 \%$
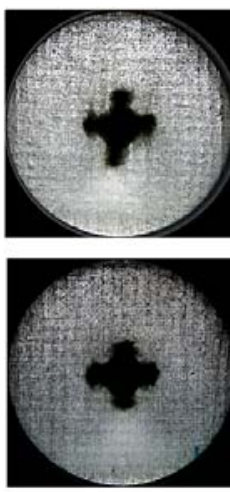

Fig. 3. Imapact damage in laminates modified with 1-7\% nanoparticles in dry (upper row) and wet ( $0,5 \%$ water absorbed)

Impact energy 3J

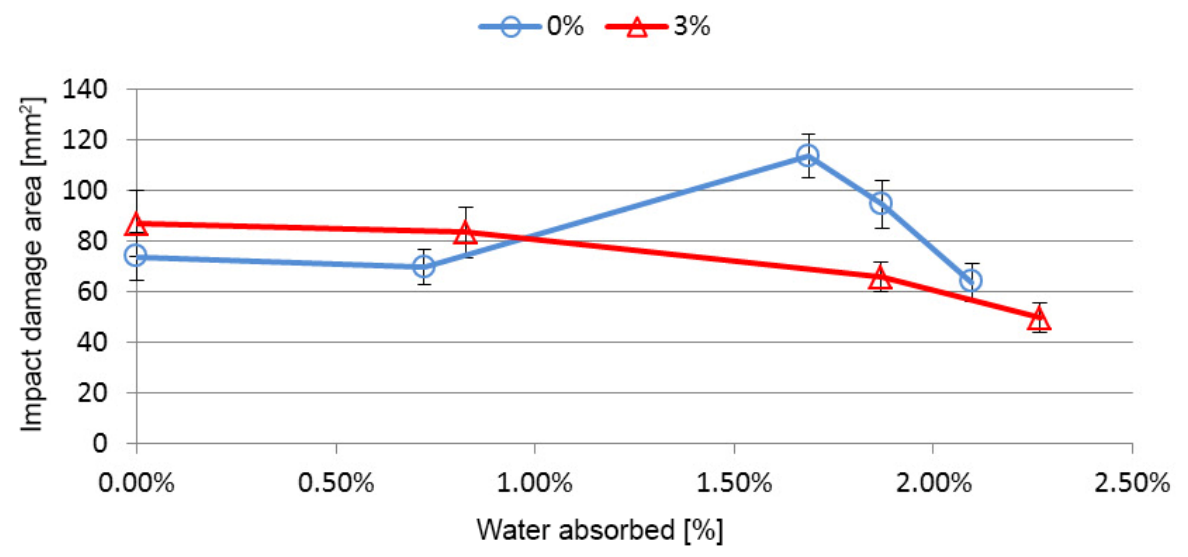

Fig. 4. Impact damage area as a function of percent water absorbed by the specimens with $0 \%$ and $3 \%$ nanoparticles. Impact energy 3J

Figs. 5ab illustrate SEM micrographs of dry (a) and wet (1.7\% water absorbed) specimen modified with 3\% nano- $\mathrm{SiO}_{2}$ after $3 \mathrm{~J}$ impact. Typical impact failure modes observed in this illustration are numerous matrix cracks (arrows). Nanoparticles cannot be observed at this magnification (100x). In Fig 5b debonded fibres are demonstrated (arrow) which is the effect of water immersion. This effect was observed in the previous study [7]. It appears that the same effect (debondings) could be observed at nanoparticle /matrix interfaces following water exposure which resulted in the change of failure mode observed for impacted specimens in wet condition. The weakest point in the material with up to ca. $2 \%$ water absorbed was the matrix with numerous debonded nanoparticles which prevented fibre fracture at $3 \mathrm{~J}$ impact energy. The presence of debonded nanoparticles accounts for the less severe failure in water affected specimens. 

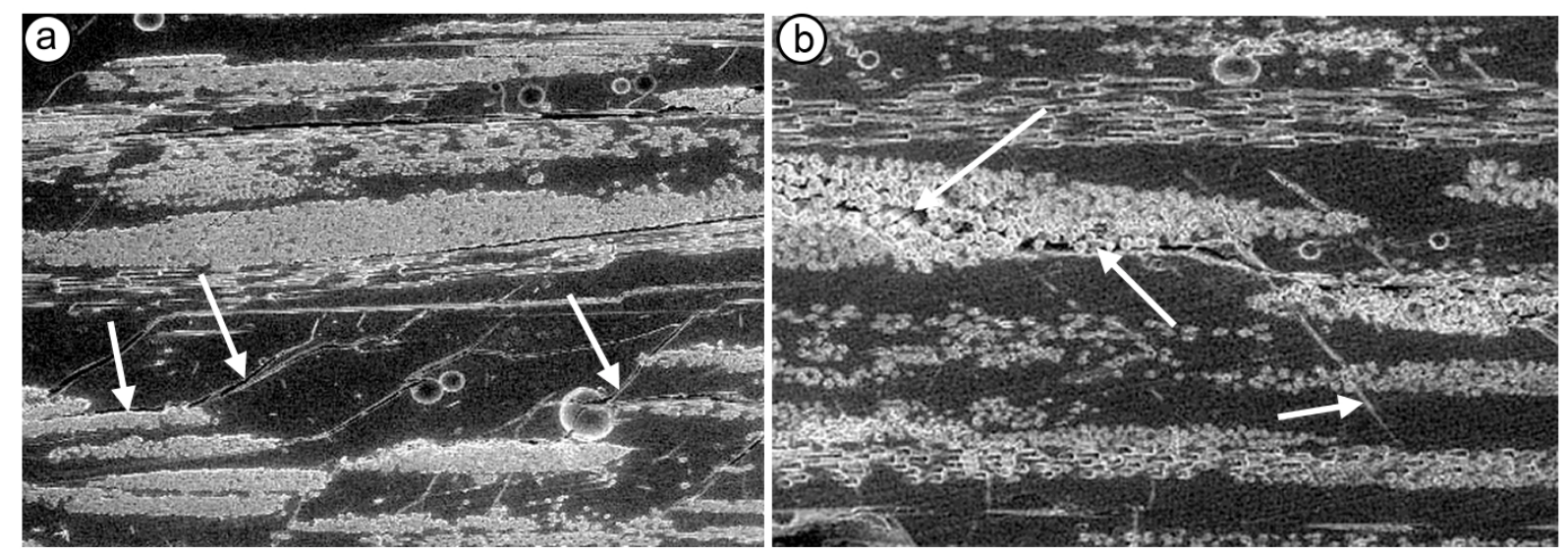

Fig. 5. SEM micrographs of dry (a) and wet (b) (1,7\% water absorbed) specimen modified with 3\% nano-SiO2 after $3 \mathrm{~J}$ impact. Arrows show matrix cracks and debonded fibres

\section{CONCLUSIONS}

Impact behaviour of glass fibre /epoxy composites with nano- $\mathrm{SiO}_{2}$ modified resin was studied in terms of low velocity impact after water exposure. Nanocomposites with $1 \%, 2 \%$, 3\% 5\% 7\% nano- $\mathrm{SiO}_{2}$ (Nanopox- Evonic) were investigated. Peak impact load and impact damage area as a function of nanoparticle contents were compared for dry specimens and for samples exposed to water ( $0.7 \%$ wt. $1.7 \%$ water absorbed) at $1 \mathrm{~J}, 2 \mathrm{~J} 3 \mathrm{~J}$ impact energies. The following conclusions have been drawn:

1. For unmodified composite peak force was higher than for 3\% modified specimens and higher for dry specimens than those exposed to water.

2. Matrix cracks were the dominating failure mode in dry specimens both unmodified and the modified.

3. Water exposure prevented early fibre fracture in nanocomposites due to nanoparticles debonding, which is a proposed energy absorption mechanism.

\section{REFERENCES}

1. Reis P.N.B., Ferreira J.A.M., Zhang Z.Y., Benameur T., Richardson M.O.W.: Impact strength of composites with nano-enhanced resin after fire exposure. Composites: Part B, 56 (2014), 290295.

2. Saber-Samandaris S., Khatibi A.A., Basic D.: An experimental study on clay/epoxy nanocomposites produced in a centrifuge: Composites Part B, 38(1), (2007),102-7.

3. Hosur M.V., Chowdhury F., Jeelani S.: Low velocity impact response and ultrasonic NDE of woven carbon/epoxy - nanoclay nanocompositres. Journal of Composite Materials, 41 (2007), 2195-212.

4. Evonik Industries - Specialty Chemicals. Evonik. http://corporate.evonik.com/ Online access: 20.01.2014. 
5. Zeng Y., Liu H.Y., Mai Y.W., Du X.S.: Improving interlaminar fracture toughness of carbon fibre/epoxy laminates by incorporation of nano-particles. Composites Part B: Engineering, 43(1) (2012), 90-94.

6. Imielińska K., Guillaumat L.: The effect of water immersion ageing on low- velocity impact behaviour of woven aramid-glass fibre/epoxy composites. Composites Science and Technology, 64 (2004), 2271-2278.

7. Landowski M., Budzik M., Imielińska K.: Water absorption and blistering of glass fibrereinforced polymer marine laminates with nanoparticle-modified coatings. Journal of Composite Materials, 48(23) (2014), 2805-2813. 